This item was submitted to Loughborough's Research Repository by the author.

Items in Figshare are protected by copyright, with all rights reserved, unless otherwise indicated.

\title{
The commodification of time and memory: Online communities and the dynamics of commercially produced nostalgia
}

\author{
PLEASE CITE THE PUBLISHED VERSION
}

https://doi.org/10.1177/1461444820914869

\section{PUBLISHER}

SAGE Publications

VERSION

AM (Accepted Manuscript)

\section{PUBLISHER STATEMENT}

This paper was accepted for publication in the journal New Media and Society and the definitive published version is available at https://doi.org/10.1177/1461444820914869. Users who receive access to an article through a repository are reminded that the article is protected by copyright and reuse is restricted to noncommercial and no derivative uses. Users may also download and save a local copy of an article accessed in an institutional repository for the user's personal reference. For permission to reuse an article, please follow our Process for Requesting Permission.

\section{LICENCE}

CC BY-NC-ND 4.0

\section{REPOSITORY RECORD}

Niemeyer, Katharina, and Emily Keightley. 2020. "The Commodification of Time and Memory: Online Communities and the Dynamics of Commercially Produced Nostalgia”. Loughborough University. https://hdl.handle.net/2134/10265807.v1. 


\section{The commodification of time and memory}

\section{Online communities and the dynamics of commercially produced nostalgia}

The role of media texts, technologies and consumption practices in the production of nostalgia has been explored by various recent studies (e.g. Menke 2017; Niemeyer 2015, 2014; Pickering \& Keightley 2014). This body of literature has increasingly moved away from a straightforward notion of either media or their users 'being nostalgic' towards a sense of media and their users being intertwined in a performative process. This kind of remembering practice at once seems to involve the pleasure of cultural consumption associated with mediated nostalgia (very often the content or experience of these 'nostalgias' is related to the memory of media devices and their texts and technologies, but also consumer products or ritual leisure activities of the past) alongside a more profound search for identity and 'home', intermingling the playfulness of pastiche and the fulfilment of consumerist desires with a search for temporal moorings, mnemonic connections and narrative identities.

Despite this move towards an examination of the processual dimensions of nostalgia, research on online communities expressing nostalgia is scarce (De Seta \& Olivotti, 2016; Kalinina and Menke, 2016). More precisely there has been a lack of analysis which examines the very specific ways in which the online environment configures the relationship between the processual dynamics of nostalgia which allow for both creative and conservative modes of identification and the commercial exploitation and commodification of the very nostalgia produced and articulated in online communities. It is this lacuna that our paper seeks to address by asking: how are nostalgic texts mobilized on social media platforms for commercial purposes, and how are nostalgic, affective communities themselves commodified in this process? While all online communities have the potential to be sites for the articulation of nostalgic modes of remembering, our concern is with the deliberate elicitation and commercial exploitation of nostalgia in online communities developed for this purpose.

This article introduces the results of an empirical case study of one of the most important 'nostalgic' businesses operating on Facebook (FB): DoYouRemember.com (DYR), a start-up that defines itself as being 'a media company devoted to all things nostalgia' (Facebook). In December 2018, their page had received 6,077,021 likes. In September 2019, they count 6,077,021 likes. The company mainly publishes North American popular consumer and media culture dating between the 1960s and 1990s, always accompanied by the question 'Do you remember?'. The case study research is based on quantitative content analysis, qualitative textual analysis and interviews with the company CEO and staff to show how nostalgic temporalities are structured and framed, firstly by the $F B$ platform itself and secondly by the algorithm DYR employs. The company programs most of its publications within a precise time-slot. This prefabricated and business-orientated way of publishing nostalgic content on $F B$ creates a specific temporal mode of consumption and experience of time.

We discuss the theoretical frames and concepts necessary to the analysis of nostalgic online communities and their temporal features, most specifically the relations of nostalgia to time, memory and the political economy of the Web. The article tackles the 
following specific questions: What kinds of memories are shared on the main $F B$ page of the company and how are they aggregated? What role and degree of temporal freedom do the users of DYR have and what is the relationship between exploitation and agency in the production and performance of commercially driven nostalgia? Who are the actors behind the scene and what kind of corporate strategies are at work? We conclude by suggesting that a delicate dance between audience creativity and the limits placed on this by commercial imperatives is crucial to understanding the performance of nostalgia online. We discuss the analytical frameworks this research offers for future work on the (online) 'nostalgia business', its economic and political dimensions and the abuses and possibilities of what could be labelled "commodification of time".

\section{Nostalgia, Memory and Online Communities}

Memory and nostalgia are intertwined modes of relating to time. They both implicate the past, present and future and emerge in the correlation and interaction of these three temporalities. By remembering the past in the present and often with an orientation to the future, particular pasts are prioritised over others and while some memories blossom, others remain latent and forgotten. This is the case in individual mnemonic practices and also in collective, social or institutional aspects of memorization or commemorations. In this sense, both, nostalgia and memory practices can be seen as being essential and useful to maintaining identities as they involve the selection and synthesis of experience into meaningful narratives (Wilson, 2005), and also as being responsible for social amnesia (Doane and Hodges, 1987). However, nostalgia is not reducible to remembering - it is a specific affective modality of engaging with the past. Bonnett in his challenge to westerncentric conceptualisations of nostalgia states: 'The paradox is that nostalgia offers and reflects the turbulence of identity and meaning that is so typical of modernity and yet it strives to overcome modernity' (2016: 154). This paradox is also omnipresent in current reflections on nostalgia within media and communication studies. Mediated memories can become triggers for nostalgia: for example a friend's photograph of a holiday trip may produce nostalgic constellations of affect: a desire for a lost past in contradistinction from a present deficient in some way. Memory is not, in this sense, a feeling, but a potential trigger of feelings. Nostalgia is of course an important part of memory studies but as Attia and Davis (2010) have shown, nostalgic feelings can also emerge without the work of memory or recall as a yearning for the future. While they overlap and work in concert, nostalgia cannot be seen as a simple sub-category of memory as it exceeds the latter's "cognitive territory" (Bonnett 2016: 17) and therefore requires its own specific research approaches.

Located between remembrance and forgetting, idealization and creativity, nostalgia is a recollection of times and places that are no more, no longer accessible or perhaps never were. It can also refer to a desire for a return to a past time that we never experienced or the regret for a past that never was, but that could have been, or for a future that never will be. Nostalgia often still suffers from a reputation for being superficial. The works by Jameson (1991) on contemporary forms of nostalgia as a product of both consumer society and of late modernity, as well as those by Davis (1979) are but two examples of this kind of pejorative assessment. Without denying that nostalgia is often a tool of economic and political expropriation, its status as a dialectical, western, postcolonial construction which is inevitably retrogressive to modernity has shifted somewhat. In the mid-2000s, Keightley and Pickering (2006) launched a call for rethinking the place of 
nostalgia in sociological research in order to recognize (but not guarantee) its creative and progressive potential, and in the same year the more constructive nature of nostalgia as a way for overcoming personal crises of the present was empirically demonstrated (Arndt et al., 2006). The publication of a special issue of Memory Studies on the historical misconceptions about nostalgia finally opened the way towards a more performative approach to nostalgia (Dames, 2010) and a transition to the verb 'to nostalgize' (Arndt et al., 2015; Niemeyer, 2014) became possible. A more empirically informed exploration of the multiple and diverse relationships between the media, communications and nostalgia began to emerge in the mid-2010s (see for example Lizardi, 2015; Niemeyer, 2014; Menke 2017; Schrey 2017; Sielke 2017). While nostalgia has become of increasing concern for media and communication scholars ${ }^{1}$ reflection on methodological and conceptual approaches - especially when it comes to the question of how and why nostalgia is produced and performed in online activities and communities - remains rare.

Research on online communities has exponentially increased over the last decades. Studies dealing with political engagement on or via the Web have shown the potential and the limits of online activities and community building (e.g. Sedda, 2015; Mabi, 2014; Granjon, 2010; Kaun 2017) for feminist movements (Jouët et al 2017; Rentschler and Thrift, 2015), ecologists and online health forums (Méadel, 2014), to name just a few examples. At the same time, with the arrival of Web 2.0, a protean mnemonic universe has also taken shape and numerous scholars have concerned themselves with the digital articulation of memories (e.g. Ernst, 2013; Reading, 2011) or specific modalities of digital forms of remembering (e.g. Casalegno 2006; Hoskins, 2017). Working across and between research on online communities and digital time and memory offers the opportunity to see nostalgia not only as being part of a mnemonic process but also a social engagement with the present and the future. Kalinina and Menke (2016) made a first step in this direction by focusing on post-soviet nostalgic online communities. De Seta and Olivotti (2016) tackled the question by analysing online Hong Kong nostalgia. What these studies have not engaged with thus far in the ways in which nostalgia is produced, exploited and circulated in online communities which are not cause or issue based, and are instead part of an implicitly commercial enterprise in the interests of extracting economic value from the process of nostalgizing.

Nostalgia has been mobilised as a commercial strategy by media and other cultural industries (Cross, 2017), marketing companies (Kessous and Roux, 2012), advertisers (Keightley and Pickering 2014; Fantin 2014) and other consumer-orientated institutions and actors (Holbrook, 1993) for decades. This is also the case when nostalgia moves online. As Iosfisidis and Wheeler (2016) note 'Online social networking sites' both 'change the face of business as we know it (for example, they enable the creation of a brand name; targeted advertising marketing; and so on)' and 'allow greater citizen participation in the dissemination of information and creation of content'. Research to date on online nostalgia has been focused on peer-to-peer, independent or 'bottom-up' social communities, emphasizing the latter affordance. Attention has been paid to the progressive potential of audiences' nostalgic practices of engagement (Kalinina and Menke, 2016) or to the ephemeral standardized social media time of mnemonic online communities on $F B$ (Kaun and Stiernstedt, 2014) but a commensurate critical focus on the practices involved in the commercial exploitation of nostalgia in online environments is routinely overlooked, especially the work of companies that we might characterise as explicitly 'nostalgia businesses' which seek to monetize the process of nostalgizing. It remains unclear how, for example, when we move our analytical focus online, 
particularly in relation to the exploitation of social networking platforms, the extent to which the conceptual and methodological separation between creative, vernacular nostalgic activity which allows for the mobilization of fondly remembered pasts in the interests change and transformation in the present and future, and the corporate fixing of a sanitized past, oriented solely to a fantasy of a lost past and emptied of progressive potential remains sustainable.

In order to address this question, we need to adopt an analytical focus which attends to the ways in which nostalgia is produced in commercially constructed online communities through the commodification and standardization of time. This means understanding how audiences are strategically and potentially engaged in nostalgizing and how user activity can be created, managed, structured and finally exploited for profit. ${ }^{2}$ At the same time it is necessary to consider how audience activity is able to exceed the commercial imperatives which solicit their activity and, by virtue of the structure and function of SNS platforms, in our case $F B$, are able to realise possibilities for the subversion and creative appropriation of commercial content and structures for the purposes of progressive forms of affective remembering. For example, on the one hand, user generated content, interactivity with content and public modes of engagement online are available for use by corporations, advertisers, marketing organisations, but on the other hand these processes and practices all contribute to textual instability, networked sensemaking practices and the potential for pluralized meanings to be generated.

To tackle the dynamic relationship between creative agency and commercial exploitation in online nostalgic communities and move beyond a vacillation between the 'utopian' characterisation of nostalgic engagement as a creative reworking of the present and future, or to dismiss it as a crass or trivial commercial - sometimes political - use of the past, we have drawn inspiration from the recent call in memory studies to adopt analytical strategies which built on political economy (see for example Reading, 2014). This approach encourages analytical attention to be focused on the interacting conditions which create, structure and sustain contemporary socio-technical ecologies of memory and the ways in which these shape their discursive and symbolic affordances.

\section{The online nostalgia business}

While in memory studies the adoption of economic and political economic perspectives is relatively recent ${ }^{3}$, political economic analyses of (international) media, communication and cultural industries are, of course, not new (e.g. Babe, 2009; Bouquillon, 2008; Lipschutz, 2010). In 1978 Golding and Murdock's recognised of the importance of analysing the social processes through which traditional media are 'constructed and interpreted and the contexts and pressures which shape and constrain those constructions' (Murdock, 1978: 72). Robin Mansell, amongst others, has argued for the application of these analytical principles to new media as the 'overall social and economic dynamics of the production and the consumption of new media continue to be subjects of speculation' (2003: 2). In practice this means fostering 'an understanding of pressures towards commodification of new media and is consequences for the way power is distributed' and at the same time encouraging 'the accumulation of insight into the way power is embedded in new media practices and the way this influences how people's lives are being mediated by new media' (Mansell 2003: 9-10). While for Mansell these are general principles for new media research, they can also be applied to particular new 
media texts. Recent work of this kind has ranged from critical examinations of 'platform businesses' such as Google or Amazon (Smyrnaios, 2017; Srnicek 2017), Big Data and symbolic, politico-institutional mediations (Menard et al., 2016) to conceptualisations of work and labour in the 'digital' economy (Casilli and Cardon, 2015; Fuchs and Sandoval 2014; Huws 2014), to critiques of online exploitation (Magis et al. 2017) and the socalled Californian Ideology of Silicon Valley (Morozov, 2013).

Memory studies has, somewhat belatedly, begun to recognise the various economies in which memory and remembering activities and practices are situated. Reading and Notley (2017: 235) argue that 'digital memory studies scholars need to pay more attention to the economic dimensions of digital-global memory in order to understand how local and transnational memories work in uneven and unequal ways, that result in substantial costs to both the environment and the less privileged left outside of the global north'. In response, they provide an analysis of the memory economy which emphasises the materiality of digital-global memory which is 'made of and with many objects: wires, hardware, software and all the natural and man-made resources used to make these; and it is energetic because it is made up of the labour we employ to think, act, recall, respond and share', and the 'digital inequalities in relation to digital infrastructures and environmental impact' (2017: 234-235). From a memory studies perspective, their work responds to Fuchs and Sandoval's call for a materialist analysis of digital labour which does not 'neglect that this labour is based on and only possible because there is a global division of labour, in which many different forms of labour are conducted under specific modes of production' (2014: 515). These complex networks of labour and technological infrastructures are also embedded in online memory practices, Kaun and Stiernstedt describe this phenomena as re-standardized into 'social media time' (2014: 1157). The possibility to recall the past in a digital context, from accessing our photo-archive through our smartphones or sharing our memories on $F B$, our intrinsic relations with technological devices do also make us potential users of a content that will not always need our own recall; memories are pre-fabricated (Douaud \& Niemeyer, 2018). FB encourages remembering via the timeline and Apple also interferes to make sure that the memories of their consumers stay safe and alive (I-Phone 7 - the Archives - Apple ${ }^{4}$ ). Our study demonstrates how personal memories and past times become commodified through the enactment of digital labour, exploiting the unpaid time of the group members to narrate their past for profit.

While it is important not to neglect global inequalities in the digital economy (not everyone has an iPhone or $F B$ account), it remains of concern what kinds of traces of the past are made available through digital-commercial infrastructures and the specific strategies, both of private capital and the user, are involved in their production. In our view, we need to build on the materialist analysis of digital economies of memory by keeping in view the symbolic and discursive practices the material conditions of late and platform capitalism support. In doing so it is possible to nuance our understanding of the kinds of relations with the past are brought into being under the conditions of late capitalism, how these temporal relations are themselves produced and commodified.

We therefore begin our own analysis which extends beyond the materialist concern with the inequalities at stake in the memory economy by asking: how are relations with the past triggered and produced through the particular configuration of corporate and public discourses as they are articulated commercially constructed communities explicitly designed for the purpose of nostalgic remembering? In this sense we are interested in 
establishing what kinds of corporate strategies that are deployed in order to form our relationship with the past, in this particular case nostalgia as a specific mode of relating to the past, and the affordances of social networking sites in doing so. For example, the architecture of social network sites which are utilised by nostalgia businesses such as DYR permits various forms of affective reactions. This is at once a cheap strategy for the aggregation of audiences using popular generationally and nationally specific cultural references which are then themselves commodifiable products for advertisers, and on the other providing opportunities for identification and communication around a shared cultural past. Adopting this approach invites us to confront the contradictions between the practices of commercial exploitation and agency which are intrinsic to the structural features of nostalgic remembering on social networking platforms. Or, in Reading and Notley's (2017) terms, it illuminates the dynamics of accumulation and expression of institutionalised, social and objectified memory capital through the performance of various kinds of nostalgic labour. In the following case study we attempt to reveal these performances by focusing on a very active 'nostalgic' company - Doyouremember.com (DYR) - and their use of $F B$.

\section{A multi-layered methodological approach to online nostalgia on Facebook (FB)}

With the slogan 'Nostalgia never gets old', the company DYR (created in 2012 in Florida, USA) is one example of how different types of nostalgia can be operationalised within the so-called platform capitalism (Srnicek, 2017). Asking explicitly 'Doyouremember?', the company addresses directly its community and shares mainly popular culture content of a 'joyful' past, such as pictures or extracts of television series, music clips etc. On its $F B$ account ${ }^{5}$, DYR appears not as a company at first sight but more like a memory maker on a huge scale. 4,336,438 users liked their page in 2016 and in June 2019 they count even more page likes: 6,339,228. The company is also active on other platforms such as YouTube, but their activity is largely concentrated on their $F B$ page. This is of course related to the functional possibilities that the platform itself offers. According to Van Dijck ' $F B$ is not a product, but a constantly evolving process whose changing manifestation is the result of a negotiation between owners, users, content producers, lawmakers, engineers and marketers about the control of data and technology' (Van Dijck, 2012: 152). As there is more space for interpersonal interaction and more intimate network building via messenger exchanges, emotional expressions via the like buttons and especially the possibility to easily create subgroups, $F B$ occupies and offers a special intermediate role between external and internal stakeholders and its users (Helmond et al., 2019). DYR administrates thirteen other groups that are divided into special sections such as music, books or decade driven (1960s nostalgia etc.) and can in this sense be seen as a stakeholder who does not directly affect FB but who is positively affected by the platform development itself and profits from the platforms evolution. Helmond et al. note that it is in May 2012 that "Facebook's infrastructural ambitions based on the maturation of its advertising development platform alongside its development platform" (2019: 138) have been put into effect. 2012 also marks the birth of DYR and the creation of the FB group in May 2012 coincides directly with the evolution of the FB platform which can be considered a special place of commodification from its inception: 
Facebook is engaged in the commodification of what can be understood as free labour, or what has been called immaterial labour. What distinguishes this particular social network is the way in which surveillance is fundamental to this process. Although Facebook and other Web 2.0 ventures have implemented strategies that break with those of "old" media, these (FB) sites can be situated within more general capitalist processes that follow familiar patterns of asymmetrical power relations between workers and owners, commodification, and the harnessing of audience (Cohen, 2008: 8).

As DYR focuses its activities mainly on $F B$, this case study is interested in how the company utilises the online platform and how the latter frames the nostalgic online activities. Our study therefore combines: a quantitative content analysis of the DYR $F B$ page content; qualitative analysis of audience engagement data; a semiotic analysis of the company's visual identity and two qualitative interviews with members of the DYR company. Data was gathered in two discrete weeks of data collection. Data collection in June 13-19, 2016 aimed to compile data on DYR-produced content, its circulation and user engagement. A second observation week from June 18-24, 2018 used the same coding instruments as the first observation week. A coding manual was created to describe the content type more generally (video, pictures, text, DYR 'branded') and thematically (music, advertising, leisure, brands, film, TV, fashion etc.). Concerning the main $F B$ page posts published were manually downloaded every day and coded. In addition to this, the number of 'likes' (love, cry etc.) were coded under the variable 'user engagement'. In the second observation week additional user data was collected. The first hundred most comments on each post were copied into a folder in order to keep track of how the users interact. The semiotic analysis focused mainly on how DYR packages the 'nostalgic' content by using their logo, inscriptions and colours to overlay shared media content (cf. fig. 1). It also addressed the vocabulary and rhetoric used by DYR on the website and on their $F B$ page.

\section{INSERT Fig. 1}

Via FB and LinkedIn (where we also received the biographical and educational information about the CEO and colleagues), we contacted the DYR-CEO and he answered quickly to our invitation via FB-messenger. We conducted an in-depth interview with the DYR founder and CEO (October 28th, 2016, 1h30). He gave open and detailed accounts of the development of DYR, explaining his passion for the nostalgia business and he gave direct insight into the Facebook statistics by sharing his screen with us during the Skype-interview. He also gave us the contact details of the marketing and public relation team. Informative interviews with the latter were conducted a few weeks later (November $10^{\text {th }}, 2016,0 \mathrm{~h} 40$ ). These interviews helped to clarify part of the company structure, but they aimed also to explore finance and corporate structures, business strategies as well as its relationship to nostalgia and the way the company deals with the user engagement. The marketing and public relation team requested we did not mention their names in our work despite this information being publicly available, so we have not named them explicitly.

\section{From live-nostalgia to the exploitation of personal narratives}


The CEO was born in New York in 1961, is co-founder and president of DYR. He studied communication at the Washington State University. As he explains during the interview, DYR goes back to an old fascination with nostalgia. In the nineties, he published a number of books with the title 'Do you remember TV? The book that takes you back' or 'Do you remember technology?' (Chronicle books). Later he saw the opportunity to go revive DYR using a different medium - the Web. In 2010/11, the CEO met Richard Bronson who was formerly known as a co-founder and advisor to DYR (cf. LinkedIn). In his interview the CEO refers to an unnamed investor as being part of past difficulties of the business:

DYR had a business partner who was very strong and who had a vision for the company and I let him run it for a while and I realized that he was ruining the business and that that he was spending a lot of my money. I came back to DYR in 2015 in January and I spent like a million dollars we had 20 employees, no revenue and we were destroying the business with like 75 dollars a month. I said that this is not gonna work, I'm either gonna close this business or I'm gonna make it work.

As he maintained that 'there is potentially money in nostalgia' he opted for the latter. In 2016, Laura Schmid and Julia Welsh (names changed by the authors) joined the team in a public relations capacity (interview 2). Julia, in her mid-twenties, studied Professional Communication and Media Studies at the University of Pittsburgh and works as a Marketing Associate for Mezocliq according to LinkedIn. Laura has a BA in Politics from Princeton is also expert in communication and marketing. She is currently the chief communications officer for Mezocliq. In their official LinkedIn profiles DYR is not mentioned. During the exchanges, the DYR staff were quite vague concerning the company structure and financial details. The office is based in New York, but others work in Miami, Florida where the company was founded in 2012. The CEO who was very chatty otherwise tried to avoid talking about finance and company structures. According to him, they are seven employees and Laura seems to be the driving person in this new starting point of DYR:

My company is no longer and I am working now with Michael to help him build and monetize... awareness grow. [It's a] very young company. The CEO is gonna be the chief thinker, that is the title I wanna give him. And Julia and I want to help him. We are in the kind of marketing - PR-selling area of DYR, we are not doing content. So we are here to help develop the brand. We try to connect as many people who are passionate for nostalgia...

These examples confirm that DYR seeks to be a major player in the nostalgia business and the intention to commodify and monetise nostalgic interactions with popular cultural texts from the recent past is clearly visible. However the commodification of time becomes particularly clear via the nostalgic intentions that DYR undertakes between its (targeted) audience and the pre-emptive temporal frames of $F B$ (timeline, indication of the date of publication, possibilities of live-broadcast etc.). In other words, different temporal frames that are pre-shaped by $F B$ in the first place and used by DYR to engage 
the audience to share, to like and to tell nostalgic stories. The temporal implications of this relationship are various and evolve also with the platform's evolution itself.

\section{Automatically generated memories of North American popular culture}

The results of the two observation weeks of the main page of DYR where only the company publishes content on the wall give some important insights into the DYR business strategy (cf. table 1). The page increased significantly the number of page likes within two years from 3201321 likes in June 2016 to 5862729 likes in June 2018 which was the aim of the CEO who also underpinning in the interview that he wants to avoid to become a content aggregator - a "nostalgia BuzzFeed" - in the future by generating too much content. In contrast he is keen to create DYR as a community and online destination in its own right. However, DYR publishes 28 posts per day on average and most of these are automatically generated (every hour or even every 30 minutes). Less than $10 \%$ of the posts are DYR 'derived' content from other DYR FB pages such as DYR music. Only a small amount of the publications $(8 \%)$ is shared via other profiles and is not initially produced by DYR. Almost $30 \%$ of the content are re-shares of alreadyposted DYR content. The company uses therefore a sort of inner recycling system to repush former posts that achieved a good audience response.

\begin{tabular}{|l|l|}
\hline Results & $\begin{array}{l}\text { Observation week 1 and 2 } \\
\text { June 13-19, 2016/ } \\
\text { June 18-24, 2018 }\end{array}$ \\
\hline $\begin{array}{l}\text { Number of posts shared by } \\
\text { DYR }\end{array}$ & 396 \\
\hline $\begin{array}{l}\text { Automatically generated } \\
\text { content }\end{array}$ & $79,6 \%$ \\
\hline DYR branded content & $92 \%$ \\
\hline Re-shared content & $28,1 \%$ \\
\hline
\end{tabular}

Table 1 - The major results of the two observations weeks

Table 2 shows that the average content of the two observations weeks is highly visual and contains animated $(57,3 \%)$ or non-animated pictures $(42,7 \%)$. Most of the posts are dedicated to Film and TV Culture (cf. table 2), Celebrities and People, Leisure (such as outdoor or indoor games) or Music. Food, History and Tradition (It was Father's Day in 2016) and as well as Specific Brands (e.g. Pepsi) follow in the content list. DYR focuses on a very specific North American popular culture content that we could date between the 1950s and the 1980s. Most of the shared posts focus on white American popular culture; there are almost no pictures or videos of African American or Asian culture during both observation weeks. One exception is the advert for Pepsi (fig. 2).

\section{INSERT Fig. 2}

\begin{tabular}{|l|l|}
\hline $\begin{array}{l}\text { The content and type of } \\
\text { the shared DYR posts }\end{array}$ & $\begin{array}{l}\text { Observation week } \mathbf{1} \text { and } 2 \\
\text { June 13-19, 2016/ } \\
\text { June 18-24, 2018 }\end{array}$ \\
\hline Film and TV Culture & $26,3 \%$ \\
\hline Celebrities/people & $17,4 \%$ \\
\hline Leisure (old games etc.) & $15,2 \%$ \\
\hline
\end{tabular}




\begin{tabular}{|l|l|}
\hline Music & $14,7 \%$ \\
\hline Food & $9,2 \%$ \\
\hline Specific brands & $8,7 \%$ \\
\hline History and tradition & $6,4 \%$ \\
\hline Others & $2,1 \%$ \\
\hline
\end{tabular}

Table 2 - Average type of content on DYR

Most of the shared content is also 'DYR branded' (cf. fig. 1 et 2 and Table 1).

Likewise, the publications themselves are framed with the transversal DYR logo and the question 'Do you remember?'. This embedded branding has several functions. First of all, it repeats the firm's logo and visual narrative and affirms in this sense their enunciation status as well as their digital image within the overall structure that is $F B$. The $F B$ users know of course that it is not DYR who created the original cultural content, but the DYR branding serves to reframe the mnemonic potentialities of cultural content within a nostalgic modality and create equivalences across and between a diversity of content. Secondly, by asking the question 'Do you remember?' in the logo, the firm directly addresses its audience and triggers a potential interaction between DYR and $F B$ users - the modality of nostalgia invoked is expressly communicative in the sense that it is only through the cumulative, interactive response of users that a sense of nostalgic community which has the potential to be attractive to advertisers emerges. The question 'do you remember?' is a way to pre-frame the comments and therefore the contours of the potential nostalgic community. Most of the FB users comment 'yes' or 'no', indicating to DYR that the content engaged them. A pre-framing of communicative nostalgia is on the one hand provided by the $F B$ platform through its architecture comprised of the time-line and group structure, and on the other hand by the DYR branding. DYR uses $F B$ and its structured modes of interactivity by users to implementing an explicit visual and rhetorical strategy in order to construct an engaged and engaging nostalgic audience. This is what Coutant and Stenger (2012) call rhetoric of participation.

\section{From binary reactions to user engaged narratives about the past}

This nostalgic rhetoric also includes harnessing the page users as content generators, especially by counting on the 'superfans' as the CEO names them:

People who watch our videos, people who send us emails, who propose posts... one person we call him the grim reaper... his name is Robert. He is the guy who somehow knows when a famous person dies before he for some reasons tracks down people who die... and when they die we put them on DYR and we often have the announcement before the associated press gets it.... It's crazy, he finds it and we cannot verify...he sends us these things and I publish them, there are a lot people out there who love what we are doing.

Users and superfans in particular therefore create significant value for DYR as they actively generate original content for free (as for example the information about the death of celebrities that represent an important part of the $F B$ content, cf. fig 3), but perhaps more significantly they create a feedback system for evaluating the relative success of posts in an attention economy, actively driving the production of content and posting 
patterns of DYR. User comments and positive mnemonic responses to posts provides information to DYR about what is receiving the most attention, which is of course crucial information to generate advertising revenue. Active users and superfans contribute to the construction and development of the company and can be considered of effectively doing digital labour.

\section{INSERT Fig.3}

As the CEO notes, DYR controls posting and picks out the most 'valuable' ones from the subgroups where posts are often generated by users: 'we have an algorithm monitoring this. And if it hits a certain number of likes per group we take that post and throw it into the main. We take a lot of the stuff of the groups and turn them into posts'. At the same time he considers that this activity gives users a kind of public recognition of their mnemonic labour: 'It also helps the group you know. They end up seeing great responses from their posts when we move them. When we move a post from the group to the page they get thousands of likes. When they don't get 1000 of likes in an hour we take it down'. DYR publications are widely shared (6 550118 shares for the two observations weeks combined), provoke a huge amount of reactions (3 784294 likes, tears and loves etc. for the two observations weeks combined) and receive numerous comments, approximately 904 comments in average per post on the DYR FB page. While most of the users engage via the 'like' button, share the publications or answer to the 'Do you remember?' question with a simple 'yes' or 'no', if a significant or detailed memory is triggered, users tend to write longer comments by evoking detailed personal memory narratives (fig. 5) and they sometimes even add personal archive pictures. This is exactly the aim of DYR. The company is interested in the quantitative and qualitative reactions to posts in order to deliver the company strategy, as the CEO states: 'These people you... you ask them what was their first car... we have like 10000 car pictures showing up, we encourage people to tell their stories'. It is the clear demonstration of communicative interaction, the level and duration of engagement and its relative stability which makes the nostalgic community commodifiable. This commercial agenda is elided by the PR representatives: 'When we joined the CEO we thought that there is this great residence of emotion and it hits a chord and it makes people smile and we want to bring joy to the world' (Laura interview). What this does indicate is the importance of the affective elements of nostalgia to the success of maintaining user engagement: positivity via the elevation of the pleasure of longing for the past over the more painful recognition of loss and lack in the present which is intrinsic to nostalgia, has to be relentlessly stimulated and protected.

Another type of user engagement goes further.

\section{INSERT Fig. 4}

This post about Dan Blocker illustrates how the personal memories of users become implicated and embedded in DYR. The third comment is particularly striking as it does not only tell the short story of a lonely army wife in Spain and the female condition of these years but also witnesses that they had no TV and that listening to the neighbours family TV made her thinking of home. She is not nostalgic for the TV show but expresses one of the originary meaning of nostalgia: homesickness. While on the one hand her 
response indicates DYRs successful capturing of attention through their nostalgic mode of address, on the other it reveals the potential for commercial nostalgic content to open up a critical, reflective space for coming to terms with the lived experience of change over time, such as geographical mobility and spatial transitions. Numerous DYR posts also become testimonies to a better (media) past where communication was less impersonal and relationships with media were more intimate. This type of comment appears occasionally and is written by users who use new technologies to express these regrets within a nostalgic community.

\section{Sanitized memories with (political) nostalgic potential}

$69 \%$ of the DYR users are women, $55 \%$ are over 34 , only few under 34 and $11 \%$ over $65^{6}$. MG bases his future advertising campaign on this: 'You know we have a page filled with women, and they are not young women, they are not Snapchat or Instagram, they are $F B$ women and so we are vigilant about keeping the page clean... not just to protect, but also we want them to share their individual memory and not to have it ridiculed. We are creating a safe destination for people to share memories ...' In this sense DYR aims to monetize the communicative activity of a social group which is potentially marginalised in other media markets. This is not in itself new: mumsnet is perhaps one of the best examples of the effective harnessing of this group, but it is DYRs emphasis on creating a sanitised and exclusively positive space for middle-aged women to articulate their autobiographically framed longings which could be characterised as a commercially constructed and exploited mnemonic 'safe space'.

DYR also counts on their fans to denunciate bad behaviour. DYR has a community manager but this person does not seem to be able to control the whole comment space. Consequently MG is happy to know that 'his' space is kept save and clean thanks to superfans and attentive users:

If somebody comes on and offends someone, ... we immediately shut them down... not just to protect, but also we want them to share their individual memory and not to have it ridiculed (...). We have a lot of super fans that will tell us if there is a problem. We do not allow disrespect and we do not allow personal promotions, and we do not allow political, spiritual or religious stuff. All of this is banned from DYR.

Consequently, there is no space for controversial political debates. One of the most recent pinned posts reminds the rules (Fig. 5).

\section{INSERT Fig. 5}

If there is resistance, it can sometimes be observed when it comes to the 'political' question itself (cf. fig 6, reaction to previous post, fig. 5) and DYR will insist and invite people to denounce bad behaviour etc.

INSERT Fig. 6 
It is notable that DYR did not censor anti-Hillary Clinton comments published the evening of the elections (FIG. 7 and 8 ) in relation to a dubious DYR post of the witch of the Wizard of $\mathrm{Oz}$ who rides a bike. DYR makes clearly a political allusion here. Most comments refer to Hillary Clinton as being the woman on the bicycle 'Hilary after the elections', 'Hilary on her way home, sure that the bike is blue' - still acceptable comments - but there is one special comment (with a red profile picture indicating the Republicans winning) that no one denounced, neither the first day nor later and it was not deleted (fig. 8).

INSERT Fig. 7 and 8

This explicitly indicates the conservative political characteristics of the DYR community, in part produced by the censoring activities of DYR itself. Whether this is reflective of an explicit political agenda of the company is unclear but it is notable that DYR has a quite similar logo as the one of the Republican party. ${ }^{7}$ (fig. 9) and proRepublican posts go uncensored (see for example fig. 10). There is also considerable consonance between the nostalgic longing stimulated by DYR, particularly the sanitised, conservative nostalgic environment which it seeks to create, and the key slogan of the Trump campaign: 'Make America Great Again'.

INSERT fig. 9

INSERT Fig. 10

\section{Conclusions}

As our analysis demonstrates nostalgic texts are mobilised on Facebook in order to maintain audience engagement and exploit the digital mnemonic labour of audiences. Audiences themselves produce and reproduce the conditions for the articulation of nostalgia utilising the popular cultural texts made available to them through the platform. Digitally enabled communicative processes such as remediation and digital archiving enable the nostalgic mobilisation of past media and popular cultural texts in commercially viable ways e.g. fast, mass distribution with minimal labour and/or expertise required. We could say that this confirms and extends Lowenthal's (2015) conception of the cultural past having an 'active afterlife' and that it is particularly true in the case of mnemonic and especially nostalgic online communities that foster a special 'feeling' of and for the past. Digital social platforms such as Facebook are based on the evocation and circulation of affect via the flattening out or relativising of expertise and critique; making them an ideal platform for nostalgic remembering, but also imaginations and memories that are still to come. 
As Kaun and Stiernstedt (2014) argue, different temporal layers are at stake when it comes to how online mnemonic communities connect and react on $F B$ :

\begin{abstract}
personalized flow annihilates the collective and simultaneous experience and meaning production. In comparison to the flow of content in radio and television, the flow in social network media undermines narrative instead of enhancing it. Page owners or moderators become increasingly focused not on narrative (history, memory, and storytelling) but on presence: on constant updates to keep the flow of the page to maintain its visibility for their members (in their newsfeeds). They follow, hence, the inherent principles of the platform and contribute to the increased flow (2014: 1165).
\end{abstract}

This predominance of immediate live reactions is also confirmed in our case, but as the administrator of the DYR is a nostalgia business, the standardized 'social media time' conceptualized by Kaun and Stiernstedt (2014) is undergoing a supplementary commodification and standardization process that uses the personal storytelling, the intimate narratives as an advertising source that exploits personal memories and nostalgic reminiscences. DYR does not only foster digital labour ${ }^{8}$ by exploiting its superfans and general users, but also does implicitly political work by commodifying the so-called 'safe space' in the process of online community building. The continual policing of the communicative nostalgic environment in the interests of protecting advertising revenue has the potential not only to be exclusionary but to promote a conservative political (and explicitly Political) agenda through the elevation of longing for the past over the other composite elements of nostalgia: loss over time and lack in the present. The hiving off of two of the three elements of nostalgia (Pickering and Keightley, 2006) undermine its progressive potential in the present. While the articulation of autobiographical narratives allows for alternative opportunities for loss and lack to be recognized and creatively and critically mobilized within the platform, the pre-framing of user engagement by DYR via the $F B$ platform limit these possibilities. Furthermore, the concrete commercialisation of nostalgia as an output of this commodification process has been amplified since the end of our study and more specifically since April 2019. As fig. 11 shows, DYR has added a shop on its main FB page; a shop that shows mainly retro objects and music and that links directly to Amazon.

\title{
INSERT FIG. 11
}

At the same time it is precisely the fact that these nostalgic modes of engagement are produced in the space between the temporal layers of social media technologies, content and practice, or what has elsewhere been called 'intermediate time' (Keightley, 2013). The historical time of popular culture and the repetitive time of remediation, the synchronic time of communication on social media, the chronological and dialogic time of the $F B$ timeline, the autobiographical time of users are synthesized in acts of longing for an idealized past. But it is the autobiographical temporalities of users enacted in their narrative responses to the incessant question 'do you remember' that exceed the disciplining practices of both the $F B$ platform and of the corporate agenda of DYR. They resist the disembedding of past popular culture in the interests of exploitation of an attention economy and are able to re-embed content within its socially experienced frameworks of meaning, linger over the significance of a very particular cultural reference, reinvesting it with creative potential for making sense of the relationship 
between past and present. This opens the possibility for other modalities of communicative nostalgia predicated on the recognition of the experience of others, rather than its flattening out in the repetitive flow of DYR branded content and pre-framed modes of response. Commercially produced and stimulated nostalgia therefore has the potential to support the building of engaged, affective communities around nostalgic media consumption and to enable creative engagements with the past, present and future in common, but this is part of a continual process of limitation and co-option by the processes of commodification intrinsic to the logic of the platform and motivations of key commercial players.

\section{References}

Arndt J, Routledge C, Sedikides C and Wildschut T (2006) Nostalgia: Content, Triggers, Functions. Journal of Personality and Social Psychology 91(5): 975-993.

Babe R E (2009) Cultural studies and political economy: toward a new integration. Toronto, ON: Lexington Books.

Baschiera S and Caoduro E (2017) The New Old: Archaisms and Anachronisms across Media. Alphaville Journal 12: 1-7.

Bonnett A (2015) The Geography of Nostalgia: Global and Local Perspectives on Modernity and Loss. London: Routledge.

Bouquillion P (2008) Les industries de la culture et de la communication: les stratégies du capitalisme. Grenoble : PUG.

Casalegno F (2006) Connected Memories in the Networked Digital Era: A Moving Paradigm. Networked Neighbourhoods : 111-125.

Coutant A and Stenger T (2012) Les médias sociaux : une histoire de participation. Le Temps des médias 18(1), $2012: 76-86$.

Cardon D and Casilli A (2015) Qu'est-ce que le digital labor?. Bry-sur-Marne : Ina.

Cohen, Nicole S. "The valorization of surveillance: Towards a political economy of Facebook." Democratic Communiqué 22.1 (2008): 5-22.

Cross G (2017) Consumed nostalgia. New York: Columbia University Press.

Dames N (2010) Nostalgia and its Disciplines: A Reponse. Memory Studies 3(3): 269275.

Davis F (1979) Yearning for yesterday: a sociology of nostalgia. New York: Free Press.

Douaud C and Niemeyer K (2018) La marchandisation du passé : Le cas d'Apple et de la préfabrication des souvenirs. Effeuillages $7: 78-84$.

Wolfgang E (2013) Digital memory and the archive. Minneapolis: University of Minnesota Press. 
Fantin E (2014) Anti-nostalgia in Citroen's advertising campaign. In: Niemeyer K (eds) Media and nostalgia: Yearning for the past, the present and the future. Basingstoke: Palgrave Macmillan, pp. 95-104.

Fevry S (2017) Sepia cinema in Nicolas Sarkozy's France: nostalgia and national identity. Studies in French Cinema 17(1): 60-74.

Fuchs C and Sandoval S (2014) Digital workers of the world unite! A framework for critically theorising and analysing digital labour. tripleC: Open Access Journal for a Global Sustainable Information Society 12(2): 486-563.

Fuchs C and Sevignani S (2013) What Is Digital Labour? What Is Digital Work? What's Their Difference? And Why Do These Questions Matter for Understanding Social Media? tripleC: Communication, Capitalism \& Critique 11(2): 237-293.

Helmond A, Nieborg, B. D and van der Vlist F. N. (2019) Facebook's evolution: development of a platform-as-infrastructure, Internet Histories, 3 (2): 123-146.

Holbrook M B (1993) Nostalgia and Consumption Preferences: Some Emerging Patterns of Consumer Tastes. Journal of Consumer Research 20: 245-256.

Huws U (2014) Labor in the Global Digital Economy: The Cybertariat Comes of Age. New York: Monthly Review Press.

Jameson F (1991) Postmodernism or the cultural logic of late capitalism. Durham: Duke University Press.

Jouët J, Niemeyer K and Bibia P (2017) Faire des vagues : Les mobilisations féministes en ligne. Réseaux 201(1) : 21-57.

Kalinina E and Menke M (2016) Negotiating the past in hyperconnected memory cultures: Post-Soviet nostalgia and national identity in Russian online communities. International Journal of Media \& Cultural Politics 12(1): 59-74.

Kaun A (2017) 'Our time to act has come': desynchronization, social media time and protest movements. Media, Culture \& Society 39(4): 469-486.

Kaun A and Stiernstedt F (2014) FB time: Technological and institutional affordances for media memories. New Media \& Society 16(7): 1154-1168.

Keightley E and Pickering M (2006). The Modalities of Nostalgia. Current Sociology 54: 919-941.

Keightley E and Pickering M (2014) Retrotyping and the Marketing of Nostalgia. In: Niemeyer K (eds) Media and Nostalgia: Yearning for the Past, Present and Future. Basingstoke: Palgrave MacMillan, pp.83-94.

Kessous A and Roux E (2012) Nostalgie et management des marques: approche sémiotique. Management \& Avenir 4(54): 15-33. 
Lipschutz R D (2010) Political economy, capitalism, and popular culture. Lanham MD: Rowman \& Littlefield Publishers.

Lizardi R (2015) Mediated Nostalgia: Individual Memory and Contemporary Mass Media. London: Lexington Books.

Lowenthal D (2015). The past is a foreign country-revisited. Cambridge: Cambridge University Press.

Magis C, Quemener N and Vörös F (2017) Exploitations 2.0. Poli - Politique de l'image 13.

Ménard M, Mondoux A, Ouellet $M$ and Bonenfant M (2016). Big Data, gouvernementalité et industrialisation des médiations symboliques et politicoinstitutionnelles. Interfaces numériques, 5(2), https://www.unilim.fr/interfacesnumeriques/3079.

Menke M (2017) Seeking Comfort in Past Media: Modeling Media Nostalgia as a Way of Coping with Media Change. International Journal of Communication 11: 626-646.

Morozov E (2013) To save everything, click here: Technology, solutionism, and the urge to fix problems that don't exist. London: Penguin Books.

Natterer K (2017) Nostalgie ALS Zukunftsstrategie Fur Unterhaltungsmedien : Empirische Studien Zu Personlicher Und Historischer Nostalgie in Medien. München : Springer.

Niemeyer K (2015) A theoretical approach to vintage, from oenology to media. European Journal of Media Studies 4(2): 85-102.

Niemeyer K (2014) Media and Nostalgia. Yearning for the past, present and future. Basingstoke: Palgrave Macmillan.

Plantin JC, Lagoze C, Edwards PN and Sandvig C (2018) Infrastructure studies meet platform studies in the age of Google and Facebook. New Media \& Society. 20(1), pp. 293-310.

Reading A (2014) Seeing red: a political economy of digital memory. Media, Culture \& Society 36(6): 748-760.

Reading A and Notley T (2015) The materiality of globital memory:

bringing the cloud to earth. Continuum 29(4): 511-521. DOI: $10.1080 / 10304312.2015 .1051807$

Reading A and Notley T (2017) 'Globital' Memory Capital: Exploring Digital Memory Economies. In: Hoskins A (eds) Digital Memory Studies: Media Pasts in Transition. New York: Routledge, pp.234-249.

Reading A (2011) Memory and digital media: Six dynamics of the globital memory field. 
In: Neiger M, Meyers $\mathrm{O}$ and Zandberg E (eds) On Media Memory. London: Palgrave Macmillan, pp.241-252.

Rentschler C A and Thrift S (2015) Doing feminism in the network: Networked laughter and the 'Binders Full of Women'meme. Feminist Theory 16(3): 329-359.

Schrey D (2017) Analoge Nostalgie in der digitalen Medienkultur. Berlin: Kulturverlag Kadmos.

Sielke S (2017) Nostalgie/Nostalgia. Imaginierte Zeit-Räume in globalen Medienkulturen / Imagined Time-Spaces in Global Media Cultures. Frankfurt: Peter Lang.

Smyrnaios N (2017) Les GAFAM contre Internet: une économie politique du numérique. Paris: INA.

Van Dijck J (2012) FB as a tool for producing sociality and connectivity. Television \& New Media 13(2): 160-176.

\footnotetext{
${ }^{1}$ See for example a recent special issue by Menke and Schwarzenegger (2017) and work by Baschiera and Caoduro (2017), Fevry 2017, Natterer 2017, Schrey 2017.

${ }^{2}$ See also Mosco 2008 for a discussion of the commodification of the audience in digital economies. http://www.gmj.uottawa.ca/0801/inaugural_mosco.pdf.

${ }^{3}$ For example a section on 'economies' of memory has been included in a new collection on 'digital memory studies' edited by Andrew Hoskins but economic aspects of memory have been relatively invisibile in readers and collections on collective memory studies prior to this.

${ }^{4}$ This video can bee watched here: https://www.youtube.com/watch? $\mathrm{v}=$ wbpBdMUrqV8 (last access, January $\left.12^{\text {th }}, 2019\right)$.

${ }^{5}$ https://www.FB.com/DoYouRemember/

${ }^{6}$ These statistics were given to us by MG during the interview via a shared screen of the Facebook analytics.

${ }^{7}$ Picture taken from Wikipedia: https://en.wikipedia.org/wiki/Republican_Party_(United States)

${ }^{8}$ In the sense of Fuchs and Sevignani (2013): Users of social media are

creative, social, and active prosumers who engage in a culture of sharing, doing, connecting and making and in these work activities create social use-values (content, social relations, co-operation). On corporate social media that use targeted advertising, this creativity is a form of labour that is the source of the value of a data commodity that is sold to advertisers and results in profits (p. 288).
} 